\title{
The effects of dietary lipids on gene expression and apoptosis
}

\author{
Gabriel Fernandes ${ }^{1 *}$, Dean A. Troyer ${ }^{2}$ and Christopher A. Jolly ${ }^{1}$ \\ ${ }^{1}$ Department of Medicine, Division of Clinical Immunology and ${ }^{2}$ Department of Pathology, The University of Texas Health \\ Science Center at San Antonio, San Antonio, TX 78284-7874, USA
}

The immune system protects the body from the constant bombardment of invading micro-organisms and other non-self molecules which could have detrimental effects on the host. A key cell in this protective system is the T lymphocyte, which plays a critical role in determining the type and magnitude of the immune response. Immunoregulation by the $\mathrm{T}$ lymphocyte is mediated, in part, by the profile of cytokines (hormone-like molecules) it produces. The fundamental mechanism leading to the propagation of $\mathrm{T}$ lymphocytes involves their activation, leading to the production of interleukin (IL)-2 and subsequent proliferation referred to as clonal expansion. Depending on the mode of activation, $\mathrm{T}$ lymphocytes will differentiate into either a helper Th-1 or $\mathrm{Th}-2$ cell, as is the case with the $\mathrm{CD}^{+} \mathrm{T}$ lymphocytes, or become a cytotoxic $\mathrm{T}$ lymphocyte as with the $\mathrm{CD} 8^{+}$cells. The Th- 1 cell produces primarily IL- 2 , interferon- $\gamma$, and tumour necrosis factor- $\alpha$ (TNF- $\alpha$ ), resulting in enhanced cell-mediated or cytotoxic responses. The Th- 2 cell produces IL-4, $-5,-6$, and -10 , generating a humoral or antibodymediated immune response.

The $\mathrm{T}$ lymphocyte cannot properly differentiate without the help of accessory cells possessing co-stimulatory receptors and/or secreting co-stimulatory cytokines. The two classic accessory cells are the B lymphocyte and the macrophage. Both these cells present antigen to the $\mathrm{T}$ lymphocyte, enabling the $T$ lymphocyte to determine the type (e.g. cell-mediated or humoral) of response necessary to successfully defend against the invading agent. This is accomplished with the help of co-stimulatory receptors and molecules produced by both the $\mathrm{T}$ lymphocyte and accessory cells. Several co-stimulatory receptors are involved, including intercellular adhesion molecules, lymphocyte-functionassociated antigen, cytotoxic $\mathrm{T}$ lymphocyte antigen-4, $\mathrm{CD} 28, \mathrm{~B} 7-1, \mathrm{~B} 7-2, \mathrm{CD} 2, \mathrm{CD} 40$ and CD40 ligand receptors. Additionally, the accessory cell can produce cytokines such as IL-1 which also assist the T lymphocyte in propagating a response (Abbas et al. 1991). These complex intercellular interactions involve the influence of fatty acid composition of membranes on membrane fluidity, membrane-associated proteins and extracellular receptors which facilitate immune system homeostasis in the host.

\section{Effect of $\boldsymbol{n - 3}$ fatty acids on the immune system}

It is well accepted that dietary fish oil (FO) has beneficial effects in ameliorating cardiovascular (CVD) and autoimmune diseases, and certain types of cancer (Calder, 1998; Fernandes \& Jolly, 1998). Interestingly, the immune system plays an important role in all three of the previously mentioned diseases. The anti-inflammatory properties of FO are attributed to two long-chain $n$ - 3 fatty acids, eicosapentaenoic acid (EPA, 20:5) and docosahexaenoic acid (DHA, 22:6). A crucial event in the pathogenesis of CVD is the occurrence of foam cells which are formed following engulfment of LDL by macrophages. $T$ lymphocytes that become autoreactive, i.e. mount a response to host molecules, lead to the development of autoimmune disorders such as rheumatoid arthritis and lupus nephritis. Furthermore, cytotoxic T lymphocytes and natural killer cells play an important role in eradicating malignant cells, thereby preventing the initiation and subsequent establishment and/or spread of tumour cells in the body. Decreased cytotoxic immune function is strongly linked to increased consumption of proinflammatory $n-6$ dietary lipids due to the elevated production of pro-inflammatory 2-series prostaglandins (PG). The mechanisms by which dietary FO-derived fatty acids decrease production of pro-inflammatory eicosanoids and various cytokines are the subject of a strong research effort.

Dietary FO has also been shown by several investigators to suppress autoimmune disease and T lymphocyte production of IL-2 and subsequent proliferation in healthy human subjects (Meydani et al. 1991; Endres et al. 1993) and mice (Yaqoob et al. 1995). In part, the mechanism appears to involve down-regulation of co-stimulatory molecules (e.g. lymphocyte-function-associated antigen, intercellular adhesion molecule 1, and CD2; Calder, 1995) on T lymphocytes as well as co-stimulatory receptors and secretions of effector molecules from accessory cells. Thus, the T lymphocyte can be modulated directly or indirectly by accessory cells such as adherent cells like the macrophage. While the majority of these studies have taken place in mice, similar effects have been found also in human subjects. For example, dietary FO suppressed the ability of macrophages to present antigen to $\mathrm{T}$

\footnotetext{
Abbreviations: AL, FO or CO-supplemented diet fed ad libitum; CO, maize oil; CR, energy-restricted (40 \% less energy than AL) diet; CVD, cardiovascular disease; DHA, docosahexaenoic acid; EPA, eicosapentaenoic acid; FO, fish oil; IL, interleukin; LT, leukotriene; PDGF, platelet-derived growth factor; PG, prostaglandin; TGF $\beta$, transforming growth factor- $\beta$; TNF- $\alpha$, tumour necrosis factor- $\alpha$; TR, thrombin receptor.
}

*Corresponding author: Professor Gabriel Fernandes, fax +1 210567 4592, email fernandes@ uthscsa.edu 
lymphocytes (Hughes et al. 1997). T lymphocyte IL-2 secretion and subsequent proliferation was significantly suppressed by FO supplementation in human subjects (Endres et al. 1993).

Recent studies have focused on elucidating the molecular mechanism(s) affected by FO on the T lymphocyte and other immune cells. Understanding the molecular events regulated by dietary FO may lead to better dietary strategies and recommendations to improve the quality of life while decreasing health care cost. It has been estimated that arthritis, the number one cause of disability in America, costs the economy approximately $\$ 54.6$ billion dollars every year in medical care and indirect costs like loss of wages (Chapkin et al. 1998). Similarly, CVD still remains as one of the foremost diseases in reducing longevity, followed by cancer.

In addition to their effects on the immune system, it is suggested that sources and amounts of dietary lipid may modulate the onset of CVD and certain cancers. Since saturated fats increase CVD and promote tumour formation, the consumption of $n-6$ lipids (vegetable fats) has increased in recent years (Fernandes \& Venkatraman, 1993). While vegetable oils rich in $n-6$ fatty acids decrease serum cholesterol, they also contain linoleic $(18: 2)$ and arachidonic $(20: 4)$ acids, which promote the synthesis of pro-inflammatory PG ( $E_{2}$ series) and leukotrienes (LT). Furthermore, $n$-6 lipids also decrease the synthesis of anti-inflammatory cytokines, such as IL- 2 and interferon- $\gamma$ by T-cells. A decrease in IL-2 production accelerates the onset and severity of autoimmune disease by increasing B-cell autoantibody production. In contrast, $n-3$ fatty acids from marine oils rich in EPA and DHA serve as precursors for $\mathrm{PGE}_{3}$ and $\mathrm{LTB}_{5}$, which decrease platelet aggregation and reduce pro-inflammatory cytokine levels (IL-1, IL-6, and TNF- $\alpha$; Fritsche \& Johnston, 1990; Calder, 1995, 1996, 1997a).

Several clinical studies in patients afflicted with rheumatoid arthritis or systemic lupus erythematosus have shown beneficial effects from FO supplementation, including moderate to significant reductions in anti-inflammatory medication dosage (Kremer et al. 1985, 1987). This is significant because many of the cytotoxic and immunosuppressive agents used have powerful side effects. Earlier studies describing either no benefit or occasionally adverse effects from FO supplementation are most probably due to the varied sources of marine oils, or a failure to prevent oxidation and rancidity during storage by supplementation of FO capsules with antioxidant. Oxidation and rancidity promote free radical formation in vivo when FO is ingested (Fernandes et al. 1996b), which could increase oxidant stress with negative effects. An added benefit of FO is amelioration of Berger's disease (immunoglobulin A nephropathy) caused by the localization of immunoglobulin A immune complexes in the kidney. In a multicentre placebo-controlled randomized trial, patients taking FO capsules (12 g daily) with sufficient antioxidant supplementation showed retardation of renal disease. After 4 years, $40 \%$ of the patients in the placebo group either died or had end-stage renal disease, whereas only $10 \%$ of the patients in the FO group showed progression of disease. It appears that purified FO with antioxidant supplements may inhibit or delay the progression of renal disease by altering the production of pro-inflammatory cytokines, growth factors, and PG, perhaps decreasing activation and localization of complement, which may suppress deposition of antigen-antibody complexes in glomeruli (DeCaterina et al. 1993, 1994; Gentile et al. 1993; Nordkild et al. 1993; Donadio et al. 1994; Lin, 1994; Morphake et al. 1994; Petterson et al. 1994).

\section{Diet, apoptosis and autoimmunity}

The immune system produces a huge excess of lymphocytes which are programmed to die unless recruited into an immune response (Illera et al. 1993). Apoptosis is a highly regulated process resulting in cell death without an ensuing inflammatory response which would potentially injure the host. Dysregulation of apoptosis in the immune system may affect developmental events in the thymus which govern lymphocyte editing and maturation processes. In addition, dysregulated apoptosis may lead to the accumulation of autoreactive or anergic lymphocytes during ageing (Troyer \& Fernandes, 1996). Experimental evidence supports a role for apoptosis in autoimmune diseases. Transgenic mice which overexpress bcl-2 develop lymphoma and autoimmune disease very similar to human lupus erythematosus (McDonnell \& Korssmeyer, 1991). Bcl-2 is a member of a family of apoptosis-suppressing proteins. In addition, baseline, unstimulated, levels of apoptosis appear to be higher in lymphocytes isolated from human lupus patients (Emlen et al. 1994), and overexpression of bcl-2 is observed in circulating $\mathbf{T}$ lymphocytes of patients with systemic lupus erythematosus (Aringer et al. 1994). Thus, an important mechanism by which autoimmunity is suppressed is via the destruction of autoreactive cells by apoptosis.

Transforming growth factor $\beta$ (TGF $\beta$ ) is an important hormone in the negative feedback regulation of immune cell activation, proliferation and subsequent effector functions. TGF $\beta$ suppresses c-myc oncogene expression in stimulated $\mathrm{T}$ lymphocytes, with the $\mathrm{CD} 4^{+}$population being more sensitive than the $\mathrm{CD} 88^{+}$lymphocytes. Furthermore, the devastating consequences seen in TGF $\beta$ knockout mice highlights its importance not only in immune function but also in overall homeostasis (Shull et al. 1992; Kulkarni et al. 1993). Interestingly, autoreactive $\mathrm{T}$ and $\mathrm{B}$ lymphocytes accumulate and inflammation is more severe in these mice, suggesting that TGF $\beta$ may play an important role in the removal of autoreactive lymphocytes perhaps via apoptosis or suppression of their function. In support of the latter hypothesis, it has been shown that TGF $\beta$ expression is associated with DNA synthesis inhibition (Bursch et al. 1993). Furthermore, enhanced expression of TGF $\beta$ was found in castrationinduced regression of prostate and in regressing tumours, suggesting its involvement in apoptosis (Bursch et al. 1993). TGF $\beta$ also induced cell death in uterine endometrial cells and hepatocytes in vitro (Oberhammer et al. 1992). In our dietary studies in B/W mice, spleens from FO-fed mice express significantly higher levels of TGF $\beta$ and lower levels of c-myc relative to maize oil (CO)-fed control mice. Thus, we studied the degree of apoptosis in the splenocytes from both CO- and FO-fed mice (Troyer \& Fernandes, 1996).

To assess apoptosis we used propidium iodide uptake and flow cytometric analysis of propidium iodide-stained apoptotic cells. Splenocytes from young FO-fed mice did not show differences in propidium iodide staining; however, 
old mice (8-10 months) exhibited significantly higher propidium iodide staining (Fernandes et al. 1996a). Splenic lymphocytes from older mice also showed a higher degree of DNA fragmentation both in the presence and absence of dexamethasone. Although the in vitro effects appear small, the in vivo cumulative effects could be enormous in regulating, in a positive way, autoimmune disease. In light of these findings, we determined the effect of $\mathrm{CO}$ and $\mathrm{FO}$ feeding on Fas expression in splenic lymphocytes. Fas is a plasma membrane receptor which induces apoptosis in cells.

Fas is a member of a receptor supergene family that includes TNF receptor, B lymphocyte antigen CD40, nerve growth factor receptor, and the T lymphocyte $\mathrm{Ox} 40$ antigen (Ogawa et al. 1995). Fas is broadly expressed on myeloid and lymphoid cells, on fibroblasts, liver cells, heart muscle, and in the ovarian follicle (Ogawa et al. 1995). The importance of Fas was the observation that the Fas gene was defective in mice carrying the lymphoproliferation (lpr) mutation, closely resembling human lupus (Ogawa et al. 1995). The result of this genetic defect was the accumulation of autoreactive $\mathrm{T}$ lymphocytes in the periphery which had escaped thymic negative selection. $\mathrm{FO}$, relative to $\mathrm{CO}$, supplementation significantly increased or maintained higher levels of Fas gene expression and protein levels in spleens from B/W mice (Fernandes et al. 1995). Enhanced apoptosis may lead to more efficient removal of autoreactive lymphocytes, thereby increasing the survival of autoimmune prone mice. Additionally, higher apoptosis was also noted in lymphoid cells from both spleen and thymic tissues from MRL/lpr mice on energy restriction (Luan et al. 1995). We recently speculated that increased apoptosis in energyrestricted and/or FO-fed mice may be due to elevated glucocorticoids, which may facilitate apoptosis in vivo relative to mice fed on $\mathrm{CO}$ ad libitum (Troyer \& Fernandes, 1996). In addition, FO-fed mice may have decreased IL-2, which may also contribute to the demise of lymphocytes, including a selective down-regulation of co-stimulatory ligands such as CD28 and/or B7-1 and B7-2 on antigenpresenting cells potentially contributing to increased apoptosis. These studies are currently underway in our laboratory.

\section{Role(s) of $n-3$ and $n-6$ fatty acids on gene expression in autoimmunity}

Studies of FO supplementation in our laboratory are conducted utilizing a semi-purified diet, adding $n-3$ lipid-rich $(100 \mathrm{~g} / \mathrm{kg})$ menhaden FO or $n-6$ lipid-rich CO containing the same level of vitamin $E(215 \mathrm{mg} / \mathrm{kg})$. When fed ad libitum to autoimmune lupus-prone NZB/NZW F1 female mice, FO ( $v$. $\mathrm{CO}$ ) supplementation delays the onset and progression of renal disease. Mice on both $\mathrm{FO}$ and $\mathrm{CO}$ gained the same amount of weight (40-45 g). Northern blot analysis of kidney extracts from 6-month-old FO-fed mice revealed no detectable levels of IL-1 $\beta$, IL- 6 , and TNF- $\alpha$ mRNA, whereas these cytokine mRNA were easily detected in 6-month-old CO-fed mice (Chandrasekar \& Fernandes, 1994). In contrast to the cytokine mRNA, FO-fed mice showed higher renal levels of the antioxidant enzymes catalase ( $E C$ 1.11.1.6), glutathione peroxidase ( $E C$ 1.11.1.9), and superoxide dismutase (EC 1.15.1.1) compared with CO-fed mice (Chandrasekar \& Fernandes, 1994). These data indicated that dietary supplementation with $\mathrm{FO}$, compared with $\mathrm{CO}$, may suppress pro-inflammatory cytokine production, which in turn could ameliorate immune-complex-mediated kidney injury by enhancing the ability of cells to dispose of harmful reactive oxygen intermediates (Chandrasekar \& Fernandes, 1994).

Next we compared hepatic microsomal membrane lipidfatty acid composition, peroxidation, and mRNA expression of antioxidant enzymes, such as catalase, glutathione peroxidase, and superoxide dismutase in 6.5-month-old $\mathrm{B} / \mathrm{W}$ mice. The results revealed that catalase, glutathione peroxidase and superoxide dismutase activities were higher in $\mathrm{B} / \mathrm{W}$ mouse liver, arachidonic and linoleic acid levels were lower, and EPA and DHA levels were higher in hepatic microsomes from $\mathrm{B} / \mathrm{W}$ mice fed on FO compared with $\mathrm{CO}$ feeding. Furthermore, significantly lower estimated peroxidation indices and generation of thiobarbituric acidreactive substances were noted in FO-fed mice. These findings suggest that one of the mechanisms by which the $n-3$ lipids may delay the onset of autoimmune disease could be through the maintenance of higher hepatic antioxidant enzyme expression and activity levels (Venkatraman et al. 1994).

In order to better understand the mechanism(s) involved in promoting renal disease, we decided to assess whether TGF $\beta$ plays a pathological role in the induction and/or progression of glomerulonephritis in $\mathrm{B} / \mathrm{W}$ mice, and whether FO supplementation can modulate the expression of TGF $\beta$. Female $\mathrm{B} / \mathrm{W}$ mice were divided into three groups fed on laboratory chow, $100 \mathrm{~g} \mathrm{CO} / \mathrm{kg}$, or $100 \mathrm{~g} \mathrm{FO} / \mathrm{kg}$. Proteinuria and serum anti-double-stranded DNA antibody levels were frequently measured to assess disease progression. Mice were killed before and after the onset of disease at 3.5 and 6.5 months of age respectively. Renal mRNA levels for TGF $\beta$ isoforms, fibronectin-1, and intercellular adhesion molecule-1 were measured using Northern blot analysis. TGF $\beta 1$ protein levels were also examined in kidneys by Western blot analysis. The results indicated that at 3.5 months of age, urinary protein levels were undetectable, very low levels of anti-double- stranded DNA were detected, and no mRNA signal could be detected for the TGF $\beta$ isoforms, intercellular adhesion molecule-1 and fibronectin-1 in either dietary group. However, at 6.5 months the FO-fed mice, compared with the lab chow and $\mathrm{CO}$ groups, had greatly reduced proteinuria and serum anti-double-stranded DNA antibodies, improved survival (CO: $100 \%$ death occurred by 8 months; FO: $50 \%$ were alive at 12 months), and renal TGF $\beta 1$ mRNA and protein levels were reduced. TGF $\beta 2$ and TGF $\beta 3$ were not significantly affected by the FO diet. Similarly, lower levels of renal fibronectin- 1 and intercellular adhesion molecule-1 mRNA were observed in FO-fed mice. These findings indicate that $\mathrm{B} / \mathrm{W}$ mice fed on a FO diet have prolonged survival and amelioration of renal disease, which may be attributed, at least in part, to lower levels of TGF $\beta 1 \mathrm{mRNA}$ and protein in the kidneys (Chandrasekar et al. 1995b).

Our next step was to investigate the immune mechanisms by which marine lipids rich in long-chain $n-3$ fatty acids inhibit autoimmune disease in female $\mathrm{B} / \mathrm{W}$ mice. In $\mathrm{CO}$-fed mice, proteinuria was detected and became progressively severe earlier than in the FO-fed mice. The average lifespan was significantly shortened in mice receiving the $\mathrm{CO}$ diet 
(266.7 (SE 12.5) d v. 402.1 (SE 26.1) d for FO). A crosssectional study at 6.5 months of age revealed an increased proliferative response to $\mathrm{T}$ lymphocyte mitogens, including bacterial superantigens and decreased serum anti-doublestranded DNA antibody titres in the FO group compared with the $\mathrm{CO}$ group. Furthermore, splenocytes from the FO group, when stimulated with concanavalin A, showed higher IL-2 and lower IL-4 secretion which was similar to levels for young (3.5 months) mice. Flow cytometric analysis of splenocytes revealed lower immunoglobulin ${ }^{+}$, higher lymphocyte endothelial cell adhesion molecule-1, and lower Pgp- $1^{+}$cells within the $\mathrm{CD} 4^{+}$and $\mathrm{CD} 8^{+}$subsets in FO-fed mice. Splenic levels of IL-2, IL-4, and TGF $\beta 1$ were elevated in FO-fed mice. In contrast, c-myc and c-ras mRNA expression and protein levels were reduced (Fernandes, 1994).

Cellular proliferation as an important pathological element in the development of lupus nephritis is well established, and may play a pivotal role in human CVD and renal disease. We therefore attempted to examine the expression of thrombin receptor (TR) and the mitogenic agents plateletderived growth factor (PDGF)-A and $-\mathrm{B}$. Weanling $\mathrm{B} / \mathrm{W}$ mice were fed either ad libitum (AL) or on an energyrestricted ( $\mathrm{CR} ; 40 \%$ less energy than $\mathrm{AL}$ ) diet supplemented with either $500 \mathrm{~g} \mathrm{CO}$ or $\mathrm{FO} / \mathrm{kg}$. Mice were killed and RNA from renal tissues were extracted from young $(3 \cdot 5-4 \cdot 0$ months of age) mice before the onset of autoimmune disease, and in old mice (8-10 months of age) after the onset. Densitometric analysis (reference gene glycerol-3phosphate dehydrogenase ( $E C$ 1.1.99.5) of blots from Northern (PDGF-A and -B) and ribonuclease protection assays for TR revealed the following results: (1) in young mice, no signal was detected for PDGF-A, -B and TR in all four groups (CO AL, CO CR, FO AL and FO CR), although the signals were readily detectable in old mice; (2) in old mice, low and similar levels of PDGF-B were detected, neither CR nor the source of the lipid used altered its expression; (3) CR significantly inhibited PDGF-A and TR expression in both CO (AL v. CR: PDGF-A 3.25-fold, TR 3.7-fold) and FO (AL v. CR: PDGF-A 4.56-fold, TR 3.6-fold), groups; (4) although FO (v. $\mathrm{CO})$ produced trends toward decreased expression, results were not statistically significant. We concluded from these studies that the suppression of renal disease in lupus-prone mice by $\mathrm{CR}$, and to a lesser extent FO, is accompanied by decreased expression of PDGF-A and TR, further confirming the possible beneficial effects of $\mathrm{FO}$ on the CVD process, as previously noted by several investigators (Troyer et al. 1997).

We also attempted to establish whether restricting dietary energy, in addition to the beneficial effect on kidney disease, could also prevent the salivary gland abnormalities common to $\mathrm{B} / \mathrm{W}$ mice. We compared the expression of TGF $\beta$ and the pro-inflammatory cytokines IL- 6 and TNF- $\alpha$ in the major salivary glands of female $\mathrm{B} / \mathrm{W}$ mice. These mice develop focal lymphocytic interstitial and periductal round cell infiltrates in salivary glands similar to human Sjögren's syndrome. Both AL- and CR-fed mice were killed at 3.5 (young) and 8.5 (old) months of age for histopathological and histomorphometric analysis as well as growth factor and cytokine protein and mRNA expression in the salivary glands. Histomorphometric analysis of salivary glands from young mice showed no differences between $A L$ and $C R$ mice, but old $A L$ (v. old CR) had a 7.3-fold higher focus score and a 34-fold increase in the percentage area of inflammation. Analysis of mRNA revealed significantly higher levels (6.8-fold) of TGF $\beta 1$ in the salivary glands of old CR mice. In contrast, CR reduced mRNA expression of the pro-inflammatory cytokines IL-6 and TNF- $\alpha$. By immunoblotting, significantly higher levels of TGF 1 protein were detected in old CR mice ( $v$. old AL, 13.2-fold). IL-6 and TNF- $\alpha$ proteins were undetectable in both young and old CR groups, whereas an increase in IL-6 (4.7-fold) and TNF- $\alpha$ (9.3-fold) was observed in old AL mice. These results indicate that amelioration of the histological severity of disease in the salivary glands of $\mathrm{B} / \mathrm{W}$ mice is parallel to, and possibly mediated by, increased expression of immunosuppressive TGF 1 and decreased expression of pro-inflammatory cytokines (Chandrasekar et al. 1995a).

\section{Effect of $\boldsymbol{n - 3}$ fatty acids on gene expression in healthy rodents}

Several studies, in addition to those described previously, have found that dietary FO suppresses gene expression in the immune system. Feeding $100 \mathrm{~g}$ FO/kg to mice significantly suppressed IL-1 $\beta$ mRNA levels in stimulated macrophages (Renier et al. 1993). Others also found that a FO-enriched diet reduced the levels of IL-1 $\beta$ and TNF- $\alpha$ in activated spleen lymphocytes (Calder, 1997b). Thus, the precedence has been established that dietary FO modulates gene expression. However, FO contains other immunomodulatory components than just $n-3$ fatty acids, making it imperative to study the enriched $n-3$ fatty acids in FO, such as EPA and DHA, separately in vivo.

Recently, short-term ( $10 \mathrm{~d})$ studies conducted in healthy young female C57B1/6 mice showed that feeding highlypurified EPA or DHA influenced lymphocyte gene expression relative to arachidonic acid-fed controls (Chapkin et al. 1998; Jolly et al. 1998). Mice were fed on one of four semi-purified diets containing $30 \mathrm{~g}$ total lipid/ $\mathrm{kg}$ for $10 \mathrm{~d}$. The diets differed only in their fatty acid content by substituting highly-purified ethyl esters. The benefit of this strategy is that other immunomodulatory compounds like cholesterol and trace minerals are absent, allowing for a better assessment of the potency of EPA and DHA themselves. The control diet contained $30 \mathrm{~g}$ safflower oil ethyl esters $/ \mathrm{kg}$, while the remaining three diets contained $20 \mathrm{~g}$ safflower oil ethyl esters plus $10 \mathrm{~g}$ arachidonic acid (triacylglycerol form), EPA ethyl esters or DHA ethyl esters (Jolly et al. 1998). The authors found that both EPA and DHA feeding significantly blunted IL-2 secretion and subsequent T lymphocyte proliferation in response to the polyclonal mitogen concanavalin A, relative to the arachidonic acid and safflower oil diets which did not differ at all (Jolly et al. 1997). This correlated with the reduced delayed-type hypersensitivity response to purified protein derivative in the footpads of mice fed on the EPA and DHA diets (Hosack-Fowler et al. 1993a). Interestingly, basal and activation-induced mRNA levels of IL-2 were not significantly reduced by dietary EPA and DHA, while message levels for IL-2R $\alpha$ were decreased (Jolly et al. 1998). On the other hand, basal mRNA levels of protein kinase $C \alpha$ and $\beta 1$ were significantly elevated in DHA-fed mice relative to the EPA, arachidonic acid and safflower oil 
groups, while the $\zeta$ isoform was relatively unaffected (Chapkin et al. 1998). Taken together the previously described findings suggest that dietary $n-3$ and $n-6$ fatty acids selectively modulate lymphocyte gene expression, which may involve both pre- and post-transcriptional events. This is the first direct evidence in vivo showing that the EPA and DHA enriched in FO has potent anti-inflammatory properties.

Additionally, FO-fed rats showed induction of hepatic peroxisomal acyl-CoA oxidase mRNA expression $7 \mathrm{~d}$ post feeding, while at $14 \mathrm{~d}$ mRNA levels were lower relative to $\mathrm{CO}$ controls. Similarly, acyl-CoA oxidase mRNA was induced in muscle, kidney and small intestine (Clarke et al. 1997). Collectively, these studies show the powerful and selective effects of dietary $n-3$ fatty acids on gene expression.

\section{Intracellular signalling pathways influenced by $n-3$ fatty acids}

Fatty acids can potentially modulate gene expression directly or indirectly by altering the membrane fatty acid composition (Jump et al. 1997; Chapkin et al. 1998). Clarke \& Jump (1996) have shown that feeding $50 \mathrm{~g}$ FO/kg diet suppressed the transcription of the fatty acid synthase ( $E C$ 2.3.1.85) gene. This was the first indication that dietary $n-3$ fatty acids influenced gene expression by a nuclear event via an unidentified suppressive factor(s). Given that dietary FO suppresses several lipogenic and glycolytic enzymes, this putative mechanism may have broad implications. More recently, additional work has been conducted on the effect of dietary FO on the peroxisomal proliferator-activated receptor- $\alpha$ (Ren et al. 1997). The peroxisomal proliferator-activated receptor- $\alpha$ is activated by fatty acids and is known to inhibit the transcription of select genes by competing for the DNA binding sites of stimulatory transcription factors. Feeding peroxisomal proliferator-activated receptor- $\alpha$-deficient mice on a $100 \mathrm{~g} \mathrm{FO} / \mathrm{kg}$ diet did not significantly influence the down-regulation of fatty acid synthase gene expression, indicating that the peroxisomal proliferator-activated receptor- $\alpha$ pathway is not involved. However, the ability of the $n-3$ fatty acids to suppress acyl-CoA oxidase was blocked in the peroxisomal proliferator-activated receptor- $\alpha$-deficient mice (Ren et al. 1997), suggesting two alternative pathways for polyunsaturated fatty acids to regulate gene expression. The specific factor(s) regulating $n-3$ fatty acid suppression of fatty acid synthase transcription remain elusive.

Alternatively, fatty acids could exert their physiological effect via the addition of CoA, which allows them to be esterified onto various phospholipids. The classic effect of feeding FO is a decrease in the $n-6$ fatty acid arachidonic acid and concomitant increase in the $n-3$ fatty acids EPA and DHA in splenic lymphocyte membrane lipids. This effect is observed whether $100 \mathrm{~g} \mathrm{FO} / \mathrm{kg}$ diet is fed to lupus-prone mice (Fernandes, 1994), $10 \mathrm{~g}$ EPA or DHA ethyl esters/kg diet are fed to healthy mice (Hosack-Fowler et al. 1993b) or highly-purified EPA and DHA are given to rats (Peterson et al. 1998). Once incorporated into immune cell phospholipids, $n-3$ fatty acids can affect a vast array of intracellular signalling pathways leading to altered gene expression.

The generation of the intracellular lipid second messengers diacylglycerol and ceramide plays a pivotal role in regulating cellular function; specifically the lymphocyte. Diacylglycerol is considered a positive effector in cell function, while ceramide is generally regarded as a cell death signal (Gomez-Munoz, 1998); however, the lymphocyte appears to be an exception because ceramide has been found to play a positive role in $\mathrm{T}$ lymphocyte proliferation (Jolly et al. 1996). Specifically, diacylglycerol activates protein kinase $C \alpha$ and $\beta 1$ and ceramide activates the $\zeta$ isoform. Recently, feeding healthy young mice on $20 \mathrm{~g}$ safflower oil plus $10 \mathrm{~g}$ EPA or DHA $/ \mathrm{kg}$ in highly-purified form blunted the kinetic production of both diacylglycerol and ceramide in concanavalin A-activated splenocytes, which correlated with suppressed IL-2 secretion and subsequent lymphoproliferation (Jolly et al. 1997). A similar effect on diacylglycerol production was seen in peritoneal macrophages from mice fed on a $100 \mathrm{~g} \mathrm{FO} / \mathrm{kg}$ diet. The specific parent phospholipids of diacylglycerol influenced by $n-3$ fatty acids has not been directly determined; however, several recent papers provided new clues. First, the in vitro administration of EPA to human peripheral blood lymphocytes does not suppress CD3-mediated $\mathrm{Ca}$ production (Vassilopoulos et al. 1997), suggesting that phosphatidylinositol is not the primary phospholipid affected. The inositol-3,4,5-triphosphate when generated induces intracellular Ca production. Furthermore, DHA was incorporated into phosphatidylcholine twice as well as into phosphatidylethanolamine, while only marginal incorporation took place in phosphatidylserine and phosphatidylinositol in human lymphocytes in vitro (Bechoua et al. 1998). Since phosphatidylethanolamine is not regarded as a significant source of diacylglycerol, while phosphatidylcholine is considered a major source, it is reasonable to suggest that $n-3$ fatty acid influence on phosphatidylcholine structure may play a key role in modulating lymphocyte function. Additionally, it is not known whether the diacylglycerol and ceramide that are produced remain biologically active or not because the fatty acid content (i.e. structure) has been greatly altered (Ahmed \& Holub, 1984; Hosack-Fowler et al. 1993b).

Dietary $n-3$ fatty acids could also alter signal transduction and subsequent gene expression by increasing the fluidity of cellular membranes. We have previously found $(\mathrm{G}$ Fernandes, unpublished results) that feeding $50 \mathrm{~g}$ FO/kg diet significantly increased membrane fluidity in lymphocytes relative to a $\mathrm{CO}$ diet. Enhanced membrane fluidity could increase or decrease the activity of enzymes associated with the membrane. Generally, integral membrane enzymes are up-regulated with increasing fluidity, while the activity of peripherally-associated enzymes may be down-regulated due to the less stable association with the membrane. Recently, it was found that dietary FO decreased phospholipase $\mathrm{C}-\gamma 1$ activity in activated lymphocytes (Peterson et al. 1998). Thus, it appears that dietary FO may modulate events proximal to phospholipase activation (i.e. tyrosine kinase activation), resulting in altered diacylglycerol and ceramide production ultimately influencing gene expression.

The classic pathway influenced by EPA and DHA is the generation of eicosanoids. Eicosanoids are oxygenated derivatives of $\mathrm{C}_{20}$ fatty acids, which have potent physiological effects. Both EPA and DHA suppress the production of $\mathrm{PGE}_{2}$ and $\mathrm{LTB}_{4}$, albeit by different mechanisms. EPA competes with arachidonic acid, which by feeding FO is already 
reduced, to yield $\mathrm{PGE}_{3}$ and $\mathrm{LTB}_{5}$ which have significantly less biological activity. In contrast DHA, which like EPA replaces arachidonic acid in membrane lipids, is not readily removed from phospholipids, therefore it suppresses $\mathrm{PGE}_{2}$ and $\mathrm{LTB}_{4}$ by the lack of a substrate and not due to the competition with arachidonic acid. Based on these observations, it was thought that the biological effects of FO were mediated primarily through eicosanoid production. However, several recent studies have shown that while altering eicosanoid production is important, it cannot completely explain the overall effects of FO on the immune system. First, one would predict that feeding arachidonic acid would exacerbate the effects of $\mathrm{PGE}_{2}$ and $\mathrm{LTB}_{4}$. In other words, lymphoproliferation would be enhanced, and thereby inflammation will become more severe due to increased $\mathrm{LTB}_{4}$-mediated immune cell chemotaxis to foci of inflammation. While eicosanoid production is elevated by arachidonic acid supplementation to human subjects, it did not influence cytokine secretion or the antibody response to influenza vaccine (Kelley et al. 1998). Furthermore, feeding arachidonic acid to healthy mice had similar effects to safflower oil feeding, while EPA and DHA fed in parallel suppressed $\mathrm{T}$ lymphocyte function, signal transduction and gene expression (Jolly et al. 1997, 1998). Thus, the effects of FO feeding on immune function involve additional mechanisms other than eicosanoid production. Our recent ongoing studies are designed to determine the effect of defined $n-3$ fatty acids (EPA and DHA) on both T lymphocyte IL-2 and T-cell receptor/CD3 receptors and co-stimulatory molecules (e.g. B7-1 and B7-2, on antigenpresenting cells) and their respective signal transduction pathways. It appears that $n$-3 fatty acids are able to down-regulate $\mathrm{B} 7-1-\mathrm{B} 7-2$ much more than $\mathrm{CD} 28$ molecules on $\mathrm{T}$ lymphocytes. Thus, studies involving co-stimulatory molecules on both $\mathrm{T}$ lymphocytes and antigen-presenting cells should provide further insight into understanding the changes occurring in signal transduction pathways and the mechanism involved in preventing the onset of autoimmune disease by $n-3$ fatty acids.

\section{Summary}

The beneficial effects of dietary FO with respect to autoimmune disease, CVD and some types of cancer are well established. Studies conducted over the last 10-15 years have established the potent effects of FO on gene expression in the previously mentioned diseases. The effects of dietary FO appear to be selective in nature, with the expression of individual genes simultaneously being increased, decreased or completely unaffected. In order to elucidate the molecular mechanism(s) involved, recent studies have focused on analysing the effects of the long-chain polyunsaturated $n-3$ fatty acids EPA and DHA which are highly enriched in FO and thought to be the primary mediators of its biological activity. Indeed, it has been found that EPA and DHA appear to both directly and indirectly modulate gene expression in vivo, depending on the gene examined. The direct effects of EPA and DHA are most probably mediated by their ability to bind to positive and/or negative regulatory transcription factors, while the indirect effects appear to be mediated through alterations in the generation of intracellular lipid second messengers (e.g. diacylglycerol and ceramide). Future studies need to be focused on further elucidation of the inter- and intracellular signalling events mediated by dietary $n-3$ fatty acids. Understanding the molecular mechanism(s) modified by dietary FO will ultimately lead to improved dietary strategies to aid in the prevention of autoimmune disease, CVD and/or certain types of cancer.

\section{Acknowledgements}

This research was supported in part by NIH post doctoral training grant NRSA AG00205 (C. A. J.) and RO1 AG10531A and AG14541 (G. F.).

\section{References}

Abbas AK, Lichtman AH \& Pober JS (1991) Molecular basis of T cell antigen recognition and activation. In Cellular and Molecular Immunology, pp. 139-167 [MJ Wonsiewicz, editor]. Philadelphia, PA: WB Saunders Company.

Ahmed AA \& Holub BJ (1984) Alteration and recovery of bleeding times, platelet aggregation and fatty acid composition of individual phospholipids in platelets of human subjects receiving a supplement of cod-liver oil. Lipids 19, 617-624.

Aringer M, Winterersberger W, Steiner CW, Kiener H, Preseterl E, Jaeger U, Smolen JS \& Graninger WB (1994) High levels of bcl-2 protein in circulating $\mathrm{T}$ lymphocytes, but not $\mathrm{B}$ lymphocytes, of patients with systemic lupus erythematosus. Arthritis and Rheumatism 37, 1423-1430.

Bechoua S, Dubois M, Nemoz G, Lagarde M \& Prigent AF (1998) Docosahexaenoic acid lowers phosphatidate levels in human activated lymphocytes despite phospholipase D activation. Journal of Lipid Research 39, 873-883.

Bursch W, Oberhammer F, Jirtle RL, Askari M, Sedivy R, Grasl-Kraupp B, Purchio AF \& Schulte-Hermann R (1993) Transforming growth factor-beta 1 as a signal for induction of cell death by apoptosis. British Journal of Cancer 67, 531-536.

Calder PC (1995) Fatty acids, dietary lipids and lymphocyte functions. Biochemical Society Transactions 23, 302-309.

Calder PC (1996) Immunomodulatory and anti-inflammatory effects of $n-3$ polyunsaturated fatty acids. Proceedings of the Nutrition Society 55, 737-774.

Calder PC (1997a) N-3 polyunsaturated fatty acids and cytokine production in health and disease. Annals of Nutrition and Metabolism 41, 203-234.

Calder PC (1997b) N-3 polyunsaturated fatty acids and immune cell function. Advances in Enzyme Regulation 37, 197-237.

Calder PC (1998) Dietary fatty acids and the immune system. Nutrition Reviews 56, S70-S83.

Chandrasekar B \& Fernandes G (1994) Decreased proinflammatory cytokines and increased antioxidant enzyme gene expression by a-3 lipids in murine lupus nephritis. Biochemical and Biophysical Research Communications 200, 893-898.

Chandrasekar B, McGuff HS, Aufdermorte TB, Troyer DA, Talal N \& Fernandes G (1995a) Effects of calorie restriction on transforming growth factor 1 and proinflammatory cytokines in murine Sjogren's syndrome. Clinical Immunology and Immunopathology 76, 291-296.

Chandrasekar B, Troyer DA, Venkatraman JT \& Fernandes G (1995b) Dietary omega-3 lipids delay the onset and progression of autoimmune lupus nephritis by inhibiting transforming growth factor $\beta$ mRNA and protein expression. Journal of Autoimmunity 8, 381-393.

Chapkin RS, McMurray DN \& Jolly CA (1998) Dietary $n-3$ polyunsaturated fatty acids modulate T-lymphocyte activation: Clinical 
relevance in treating diseases of chronic inflammation. In Nutrition Immunology: Principles and Practice (In the Press).

Clarke SD \& Jump DB (1996) Polyunsaturated fatty acid regulation of hepatic gene transcription. Lipids 31, S7-S11.

Clarke SD, Turini M \& Jump D (1997) Polyunsaturated fatty acids regulate lipogenic and peroxisomal gene expression by independent mechanisms. Prostaglandins, Leukotrienes and Essential Fatty Acids 57, 65-69.

DeCaterina R, Caprioli R, Giannessi D, Sicari R, Galli C, Lazzarini G, Bernini W, Carr L \& Rindi P (1993) N-3 fatty acids reduced proteinuria in patients with chronic glomerulonephritis. Kidney International 49, 603-607.

DeCaterina R, Endres S, Kristensen SD \& Schmidt EB (1994) N-3 fatty acids and renal disease. American Journal of Kidney Disease 24, 397-415.

Donadio JVJ, Bergstralh EJ, Offord KP, Spencer DC \& Holley KE (1994) A controlled trial of fish oil in IgA nephropathy. Mayo Nephrology Collaborative Group. New England Journal of Medicine 331, 1194-1199.

Emlen W, Niebur J \& Kadera R (1994) Accelerated in vitro apoptosis of lymphocytes from patients with systemic lupus erythematosus. Joumal of Immunology 152, 3685-3692.

Endres S, Meydani SN, Ghorbani R, Schindler R \& Dinarello CA (1993) Dietary supplementation with $n-3$ fatty acids suppresses interleukin-2 production and mononuclear cell proliferation. Journal of Leukocyte Biology 54, 599-603.

Fernandes G (1994) Dietary lipids and risk of autoimmune disease. Clinical Immunology and Immunopathology 72, 193-197.

Fernandes G, Chandrasekar B, Luan X \& Troyer DA (1996a) Modulation of antioxidant enzymes and programmed cell death by $n-3$ fatty acids. Lipids 31, S91-S96.

Fernandes G, Chandrasekar B, Mountz JD \& Zhao W (1995) Modulation of Fas apoptotic gene expression in spleens of $B / W$ mice by the source of dietary lipids with and without calorie restriction. FASEB Journal 9, A787.

Fernandes G \& Jolly CA (1998) Nutrition and autoimmune disease. Nutrition Reviews 56, S161-S169.

Fernandes, G \& Venkatraman J (1993) Role of $\omega$-fatty acids in health and disease. Nutrition Research 13, S19-S45.

Fernandes G, Venkatraman J \& Troyer DA (1996b) Interaction of vitamin $\mathrm{E}$ with $n-6$ and $n-3$ polyunsaturated fatty acids. International Society for the Study of Fatty Acids and Lipids 3 , 10-13.

Fritsche KL \& Johnston PV (1990) Effect of dietary $\alpha$-linolenic acid on growth metastasis, fatty acid profile and prostaglandin production of two murine mammary adenocarcinomas. Nutrition Research 10, 577-588.

Gentile MG, Fellin G, Cofano F, Delle Fave A, Mannan G, Iciceri R, Petrini C, Lavarda F, Pozzi F \& D'Amico G (1993) Treatment of proteinuric patients with a vegetarian soy diet and fish oil. Clinical Nephrology 40, 315-320.

Gomez-Munoz A (1998) Modulation of cell signalling by ceramides. Biochimica et Biophysica Acta 1391, 92-109.

Hosack-Fowler K, Chapkin RS \& McMurray DN (1993a) Effects of purified dietary $n-3$ ethyl esters on murine T lymphocyte function. Journal of Immunology 151, 5186-5197.

Hosack-Fowler K, McMurray DN, Fan YY, Aukema HM \& Chapkin RS (1993b) Purified dietary n-3 polyunsaturated fatty acids alter diacylglycerol mass and molecular species composition in concanavalin A-stimulated murine splenocytes. Biochimica et Biophysica Acta 1210, 89-96.

Hughes DA \& Pinder AC (1997) N-3 polyunsaturated fatty acids modulate the expression of functionally associated molecules on human monocytes and inhibit antigen presentation in vitro. Clinical and Experimental Immunology 110, 516-523.
Illera V, Perandones CE, Stunz LL, Mower DA \& Ashman RF (1993) Apoptosis in splenic B lymphocytes. Journal of Immunology 151, 2965-2973.

Jolly CA, Jiang YH, Chapkin RS \& McMurray DN (1997) Dietary $n-3$ polyunsaturated fatty acid modulation of murine lymphoproliferation and interleukin-2 secretion: Correlation with alterations in diacylglycerol and ceramide mass. Journal of Nutrition 127, 37-43.

Jolly CA, Laurenz JC, McMurray DN \& Chapkin RS (1996) Diacylglycerol and ceramide kinetics in primary cultures of activated T-lymphocytes. Immunology Letters 49, 43-48.

Jolly CA, McMurray DN \& Chapkin RS (1998) Effect of dietary $n-3$ fatty acids on interleukin-2 and interleukin-2 receptor $\alpha$ expression in activated murine lymphocytes. Prostaglandins, Leukotrienes and Essential Fatty Acids 58, 289-293.

Jump DB, Clarke SD, Thelen A, Liimatta M, Ren B \& Badin MV (1997) Dietary fat, genes, and human health. In Dietary Fat and Cancer, pp. 167-176 [American Institute for Cancer Research, editors]. New York: Plenum Press.

Kelley DS, Taylor PC, Nelson GJ \& Mackey BE (1998) Arachidonic acid supplementation enhances synthesis of eicosanoids without suppressing immune functions in young healthy men. Lipids 33, 125-130.

Kremer JM, Bigaouette J, Michalek AV, Lininger L, Huyck C, Timchalk MA, Rynes RI, Zeiminski J \& Bartholomew LE (1985) Effects of manipulating dietary fatty acids on clinical manifestations of rheumatoid arthritis. Lancet i, 184-187.

Kremer JM, Jubiz W, Michalek A, Rynes RI, Bartholomew LE, Bigaouette J, Timchalk M, Beeler D \& Lininger L (1987) Fish oil fatty acid supplementation in active rheumatoid arthritis. A double-blinded, controlled, crossover study. Annals of Internal Medicine 106, 497-502.

Kulkarni AB, Hug CG, Becker D, Geiser A, Lyght M, Flanders KC, Roberts AB, Sporn MB, Ward JM \& Karlsson S (1993) Transforming growth factor beta 1 null mutation in mice causes excessive inflammatory response and early death. Proceedings of the National Academy of Sciences USA 90, $770-774$.

Lin C (1994) Treatment of IgA nephropathy. Springer Seminars in Immunopathology 16, 121-127.

Luan X, Zhao W, Chandrasekar B \& Fernandes G (1995) Calorie restriction modulates lymphocyte subset phenotype and increases apoptosis in MRL/1pr mice. Immunology Letters 47 , 181-186.

McDonnell TJ \& Korssmeyer SJ (1991) Progression from lymphoid hyperplasia to high grade malignant lymphoma in mice transgenic for the $\mathrm{t}(14: 18)$. Nature 349, 254-256.

Meydani SN, Endres S, Woods MM, Goldin BR, Soo C, Morrill-Labrode A, Dinarello CA \& Gorbach SL (1991) Oral (n-3) fatty acid supplementation suppresses cytokine production and lymphocyte proliferation: Comparison between young and older women. Journal of Nutrition 121, 547-555.

Morphake P, Briety J, Darlametsos I, Tsipas G \& Gkikas G (1994) Alteration of cyclosporine CsA-induced nephrotoxicity by gamma linolenic acid (GLA) and eicosapentaenoic acid (EPA) in Wistar rats. Prostaglandins, Leukotrienes and Essential Fatty Acids 50, 29-35.

Nordkild PK, Graff J, Jorgensen HE \& Fugleberg S (1993) Fish oil and antioxidant supplements reduce erythropoietin requirement in haemodialysis patients. Nephrology Dialysis and Transplantation $8,569$.

Oberhammer F, Fritsch G, Pavelka M, Froschl G, Tiefenbacher R, Purchio T \& Schulte-Hermann R (1992) Induction of apoptosis in cultured hepatocytes and in the regressing liver by transforming growth factor-beta 1 occurs 
without activation of an endonuclease. Toxicology Letters 64, 701-704.

Ogawa N, Dang H \& Talal N (1995) Apoptosis and autoimmunity. Journal of Autoimmunity 8, 1-19.

Peterson LD, Jeffery NM, Thies F, Sanderson P, Newsholme EA \& Calder PC (1998) Eicosapentaenoic and docosahexaenoic acids alter rat spleen leukocyte fatty acid composition and prostaglandin $E_{2}$ production but have different effects on lymphocyte functions and cell-mediated immunity. Lipids 33, 171-180.

Petterson EE, Rekola S, Berglund L, Sundqvist KG, Angelin B, Diczfalusy U, Bjorkhem I \& Bergstrom J (1994) Treatment of IgA nephropathy with omega-3 polyunsaturated fatty acids: A prospective, double-blind, randomized study. Clinical Nephrology 41, 183-190.

Ren B, Thelen AP, Peters JM, Ganzalex FJ \& Jump DB (1997) Polyunsaturated fatty acid suppression of hepatic fatty acid synthase and S14 gene expression does not require peroxisome proliferator-activated receptor $\alpha$. Journal of Biological Chemistry 272, 26827-26832.

Renier G, Skamene E, DeSanctis J \& Radzioch D (1993) Dietary n-3 polyunsaturated fatty acids prevent the development of atherosclerotic lesions in mice. Arteriosclerosis and Thrombosis 13, 1515-1524.
Shull MM, Ormsby I, Kier AB, Pawlowski S, Diebold RJ, Yin M, Allen R, Sidman C, Proetzel G, Calvin D, Annunziata N \& Doetschman T (1992) Targeted disruption of the mouse transforming growth factor-beta 1 gene results in multifocal inflammatory disease. Nature 359, 693-699.

Troyer DA, Chandrasekar B, Barnes J \& Fernandes G (1997) Calorie restriction decreases platelet derived growth factor-A and thrombin receptor mRNA expression in autoimmune murine lupus nephritis. Clinical and Experimental Immunology 108, $58-62$.

Troyer DA \& Fernandes G (1996) Nutrition and apoptosis. Nutrition Research 16, 1959-1987.

Vassilopoulos D, Zurier RB, Rossetti RG \& Tsokos GC (1997) Gammalinolenic acid and dihomogammalinolenic acid suppress the CD3-mediated signal transduction pathway in human T cells. Clinical Immunology and Immunopathology $\mathbf{8 3}$, 237-244.

Venkatraman JT, Chandrasekar B, Kim JD \& Fernandes G (1994) Effects of $n-3$ and $n-6$ fatty acids on the activities and expression of hepatic antioxidant enzymes in autoimmune-prone NZB $\times$ NZW F1 mice. Lipids 29, 561-568.

Yaqoob P, Newsholme EA \& Calder PC (1995) The effect of fatty acids on leucocyte subsets and proliferation in rat whole blood. Nutrition Research 15, 279-287. 